\title{
Fundamentals and applications of electrochemistry
}

\author{
A. J. McEvor \\ Ecole Polytechnique Fédérale de Lausanne, CH-1015 Lausanne, Switzerland(*) \\ Dyesol Ltd. - Queanbeyan NSW 2620, Australia
}

\begin{abstract}
Summary. - The Voltaic pile, invented here on Lake Como 200 years ago, was a crucial step in the development of electrical engineering. For the first time a controlled and reliable source of electric current was available. The science of electrochemistry developed rapidly and is now a key contributor, not just to energy technology but also, for example, to metallurgy and industrial processes. The basic concepts of electrochemistry are presented, with the practical examples of its application in fuel cells, and with the perspective of the history of the subject.
\end{abstract}

\section{1. - Introduction}

Prior to Alessando Volta (fig. 1) and the invention of the Voltaic pile here in Italy in the city of Como in 1799, "electricity" implied static electricity. There were of course the experiments of Benjamin Franklin on lightning, and high voltage sources such as the Wimhurst machine which was based on charge generation by friction. However no controlled and reliable source of a continuous electric current was available. By filling that gap, Volta not only laid the foundations of electrochemistry, but also of all electrical engineering and telecommunications. The pile made possible experiments on

\section{$\left(^{*}\right)$ Retired.}

This is an Open Access article distributed under the terms of the Creative Commons Attribution License 2.0, which permits unrestricted use, distribution, and reproduction in any medium, provided the original work is properly cited. 


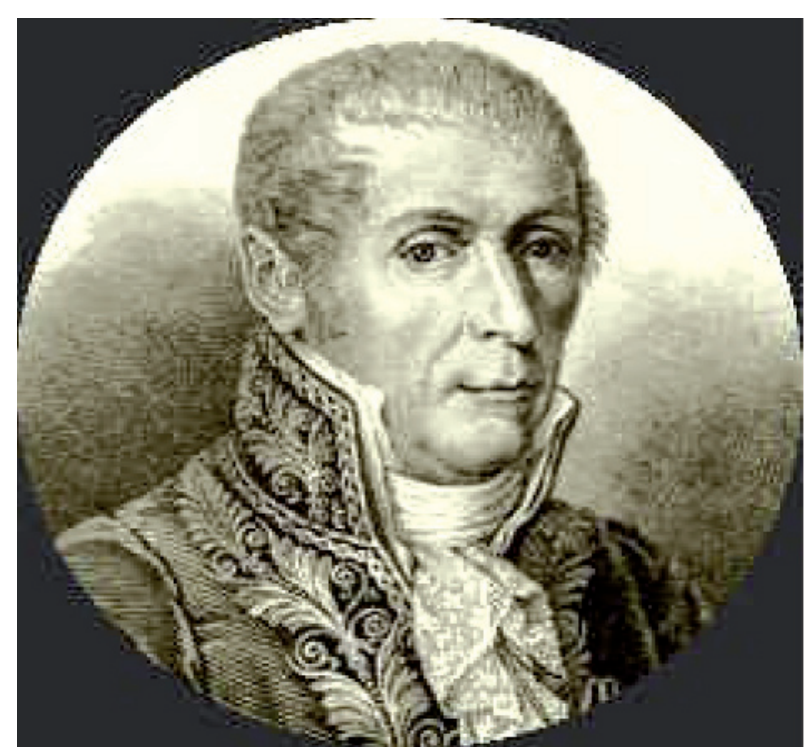

Fig. 1. - Alessandro Volta, 1745-1827, from an engraving by G. Garavaglia, 1814.

the magnetic effects of an electric current, hence electromagnets, motors and generators, but also the telegraph, all of which became realities during the 19th century.

Volta's invention rapidly attracted attention throughout Europe. For publication of his results he wrote to Sir Joseph Banks, president of the Royal Society, London on March 20 and April 1, 1800. He showed them to Anthony Carlisle, who with William Nicholson, copied the pile and within a month, May 1800, observed the "decomposition of water" to hydrogen and oxygen (electrolysis) in London, even before Volta's report had appeared in print. In fig. 2 the terminals of multiple piles in series are shown as electrolyte-filled cups. Evidently if the piles are connected to a single cup, electrolysis results. Shortly afterwards Humphry Davy discovered the alkali and alkaline earth metals by electrolysis of molten salts. This gave rise later to the Hall-Herault cell for aluminium and to electrolytic metallurgy. The reverse reaction, recombination of hydrogen and oxygen in a fuel cell to generate electricity came about 1839 through the collaboration of Christian Schonbein and William Grove (fig. 3). Electrochemistry had become a science and an engineering tool.

\section{2. - The electrochemical series}

The Volta cell demonstrates that the potentials of electrochemical reactions of metals differ, so that a potential difference can be established between them when two different metallic electrodes are in contact with an electrolyte. To each combination of electrode and electrolyte, or "half cell" a potential can be attributed corresponding to a zero-current equilibrium, again dependent on the metal and the concentration of the 

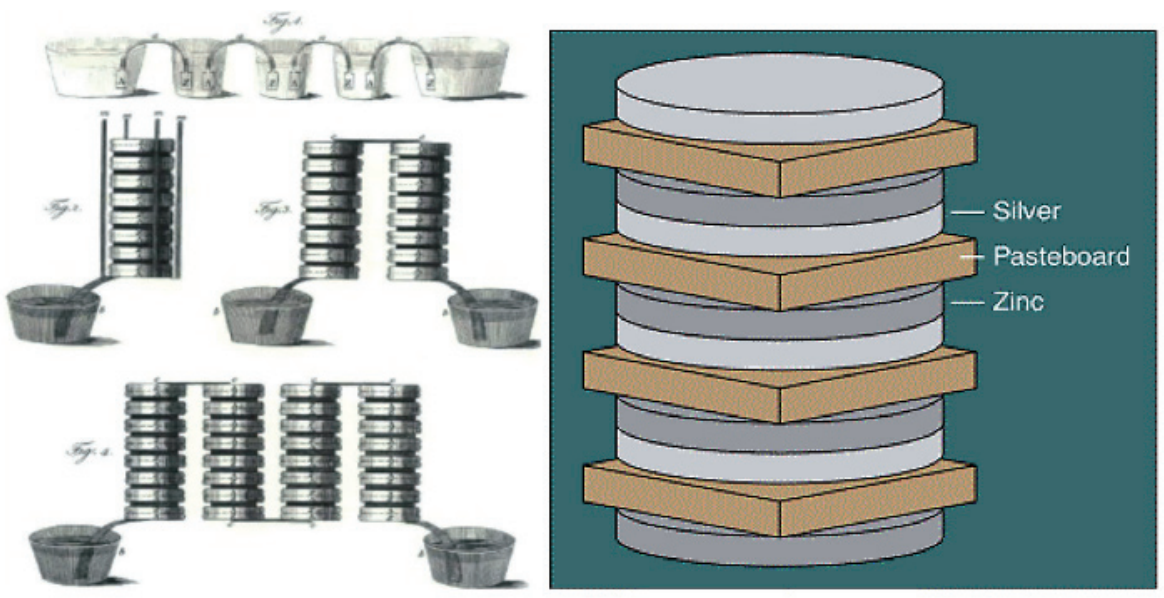

Fig. 2. - Original drawings by Volta. Top left: the "chain of cups" apparatus and the classical pile or "columnar apparatus". His figures show a single pile and series groupings of two or four piles. Right: structure of the pile, with electrolyte-saturated pasteboard separating zinc from silver or copper discs. The "chain of cups" configuration of single cells in series was to avoid short-circuits due to leaking electrolyte in a pile.

corresponding ion in the electrolyte. The standard potential of a half cell is when the ion concentration is 1 molar. The electrochemical series relates the standard electrode potentials of elements and ions, and is indicative of the potential difference in a full cell when two half cells are selected. The order shows the tendency of one element to reduce the ions of any other element below it in the series, for example $\mathrm{Zn} \rightarrow \mathrm{Zn}^{2+}$ will provide electrons to reduce $\mathrm{Cu}^{+}$to $\mathrm{Cu}$. It is the key to relating chemistry to electricity and to thermodynamics. Where the heat of formation of an ionic species is higher, so also it

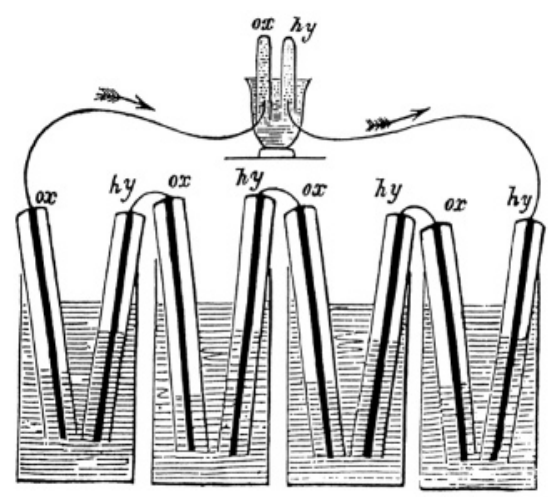

Fig. 3. - Illustration by Grove of a series connection of fuel cells operating an electrolysis cell. 
is found more negatively in the electrochemical series. In table I are some examples of the potentials at which certain ions are in equilibrium with their elements. It should be noted that the zero of the electrochemical potential scale is defined as that of elemental hydrogen in contact with an electrolyte, 1 molar in hydrogen ions.

TABLE I. - Order of some metallic elements in the electrochemical series.

\begin{tabular}{lr}
\hline $\mathrm{Li}^{+}+\mathrm{e}^{-} / \mathrm{Li}(\mathrm{s})$ & $-3.04 \mathrm{~V}$ \\
$\mathrm{Zn}^{2+}+2 \mathrm{e}^{-} / \mathrm{Zn}(\mathrm{s})$ & $-0.76 \mathrm{~V}$ \\
$2 \mathrm{H}^{+}+2 \mathrm{e}^{-} / \mathrm{H}_{2}(\mathrm{~g})$ & $0.0 \mathrm{~V}$ \\
$\mathrm{Cu}^{+}+\mathrm{e}^{-} / \mathrm{Cu}(\mathrm{s})$ & $+0.52 \mathrm{~V}$ \\
$\mathrm{Ag}^{+}+\mathrm{e}^{-} / \mathrm{Ag}(\mathrm{s})$ & $+0.80 \mathrm{~V}$ \\
$\mathrm{O}_{2}(\mathrm{~g})+4 \mathrm{e}^{-} / 2 \mathrm{O}^{2-}$ & $+1.23 \mathrm{~V}$ \\
$\mathrm{Au}^{+}+\mathrm{e}^{-} / \mathrm{Au}(\mathrm{s})$ & $+1.83 \mathrm{~V}$ \\
\hline
\end{tabular}

\section{3. - Characteristics of an electrochemical cell}

To complete an electrical circuuit, two half cells are necessary, with two electrodes, an anode and a cathode both in contact with an electrolyte, as well as an external connection between them. The electrical characteristics of such a cell are shown in fig. 4. It is immediately obvious that the system is non-Ohmic. In place of a linear current/voltage characteristic, the current rises exponentially with potential from the equilibrium point, in accordance with the Tafel equation:

$$
i=n F k \exp \left( \pm \alpha n F \frac{\Delta V}{R T}\right),
$$

where the plus sign under the exponent refers to an anodic reaction, and a minus sign to a cathodic reaction, $n$ is the number of electrons involved in the electrode reaction, $k$ is the rate constant for the electrode reaction, $R$ is the universal gas constant, $F$ is the Faraday constant and $\Delta V$ is the potential applied relative to the equilibrium. This equation will not be derived here, but it should be noted that it relates the electrochemical reaction to fundamental thermodynamic parameters, with one factor, $\alpha$, determined for the specific electrochemical reaction conditions. In fig. 4 the reactions of two half cells are shown, with different gradients of their $i / V$ characteristics. Even for the same reagents and electrochemical process, these gradients can be modified, for example by changing surface conditions of the electrode or by additives to the electrolyte as examples of electrocatalysis. The term anode or cathode is applied to one or the other of the electrodes according to whether the related electrochemical reaction is an oxidation or a reduction, irrespective of the relative potential. Therefore in an electrolysis cell where a potential is applied from the exterior across the electrodes, the anode is the positive electrode and the reaction is an oxidation; the cathode is the negative electrode, supplying electrons to 


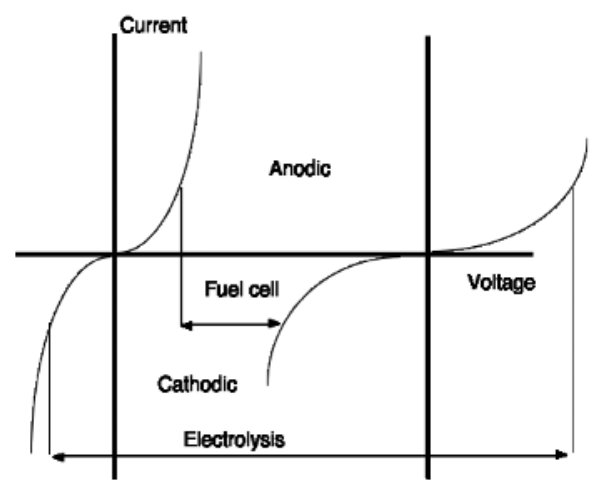

Fig. 4. - electrical characteristics of an electrochemical cell.

bring about a reduction. On the contrary, when the reverse process occurs in a battery such as Volta's or fuel cell like Grove's, there is an oxidation reaction taking up electrons at the anode, which is then at a potential negative with respect to the cathode. This electrochemical definition can give rise to some misunderstanding with electrical and electronic engineers!

In a complete cell, the currents must be identical but in opposite senses. Each reaction has a different overpotential $\Delta V$ for the same current density, and obviously this represents an energy loss for the overall reaction. Therefore to bring about electrolysis a potential difference higher than that between the equilibrium potentials must be applied, and equally the potential supplied by a battery is less than the open-circuit value. Electrocatalytic techniques are applied in practice to minimise these overpotential losses; they can also be used selectively to favour one electrochemical process over another. Examples are the lead-acid battery, which can provide an output voltage of over $2 \mathrm{~V}$, greater than that required for aqueous electrolysis which is inhibited on lead. The redox reactions of lead and its oxide are catalytically favoured. However if the electrolyte is contaminated even by minute amounts of another metal ion, electrolysis of the aqueous electrolyte takes place and the battery rapidly fails. This is why distilled water is always used in making up the sulfuric acid electrolyte for this type of battery.

\section{4. - Electrochemistry and energy - electrolysis and the fuel cell}

A major limitation in the efficiency of thermal fuel use is posed by the second law of thermodynamics, resulting in the Carnot limit, imposed by the difference of the maximum temperature of the heat source and that at which heat is discharged from an engine: maximum efficiency $=\eta=\left[T_{1}-T_{2}\right] / T_{1}$, where $T_{1}=$ source temperature; $T_{2}=$ discharge temperature, both being measured in the absolute scale $(\mathrm{K})$. An electrochemical process however is isothermal, so the Carnot restriction does not apply. This was realised as early as 1894, and clearly expressed by Wilhelm Ostwald:

"If we could have a Galvanic system, which could generate electricity directly from 


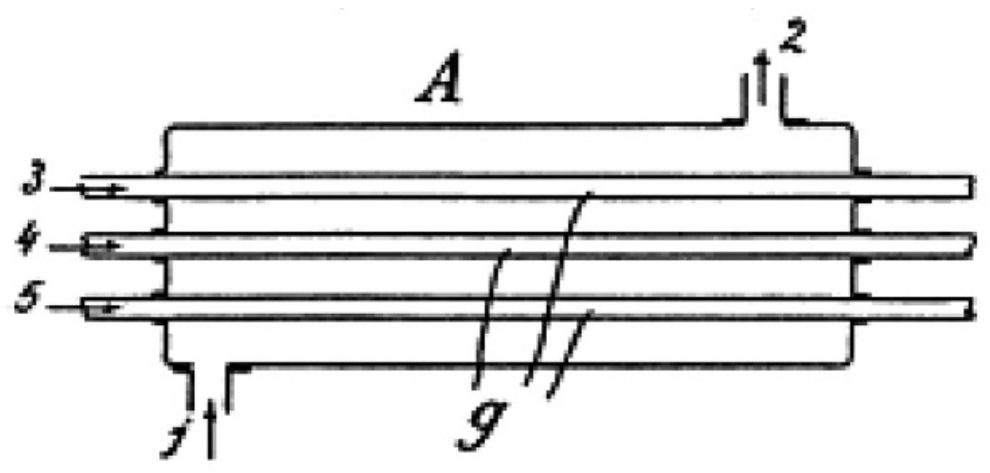

Fig. 5. - Coal gas fuel cell invented by Fritz Haber, 1905.

coal and the oxygen of the air, and that with an efficiency in any way approaching the theoretical value, then we would be in the presence of a technical breakthrough compared to which the invention of the steam engine is negligible. Just think how our industrial areas would be changed! No smoke, no soot, no steam engines or boilers, indeed no fire at all, since fire would be needed only for a few processes which could not be carried out electrically, and even these would get fewer by the day!" He clearly presented what is still an objective of research and development, an ecologically acceptable, efficient and economic energy conversion particularly for electricity generation. The analysis given by Ostwald in the 19th. century remains valid and familiar today!

In an Austrian Patent, no. 27743, filed in 1905 under the title "Procedure for generating electrical energy from coal and gasifiable fuels", Fritz Haber described what would now be recognised as a solid oxide fuel cell. Reflecting the fuel technology of the day, he proposed the use of coal gas. The glass tubes $g$ in fig. 5 would function as solid electrolytes, glass becoming quite a good oxygen ion conductor at high temperatures, in contact with metal electrodes. Haber also studied in detail what we now know as the Nernst potential. As already mentioned, the equilibrium potential of an electrochemical reaction can be influenced by operating conditions such as reagent concentration. In liquid-state electrochemistry, anode and cathode each represent a half cell whose equilibrium potential $U_{0}$ is specified by the Nernst equation:

$$
U_{0}=U^{*}-(R T / n F) \cdot \ln (\operatorname{Red} / \mathrm{Ox})
$$

where $U^{*}$ is the standard electrode potential, and (Red) and (Ox) are the actiivities of the reduced and oxidised species entering into the half-cell reaction. The activity is constant for a metal electrode, and determined by the concentration of the solute ion and its electrical charge. The maximum open-circuit potential $\left(\mathbf{V}_{\mathrm{oc}}\right)$ of the full cell is the difference between the equilibrium potentials of the anodic and cathodic half cells under the given operating conditions. Where the reagents are gaseous, such as air as oxidiser and the coal gas in Haber's cell, the reagent concentration is of course the partial pressure 


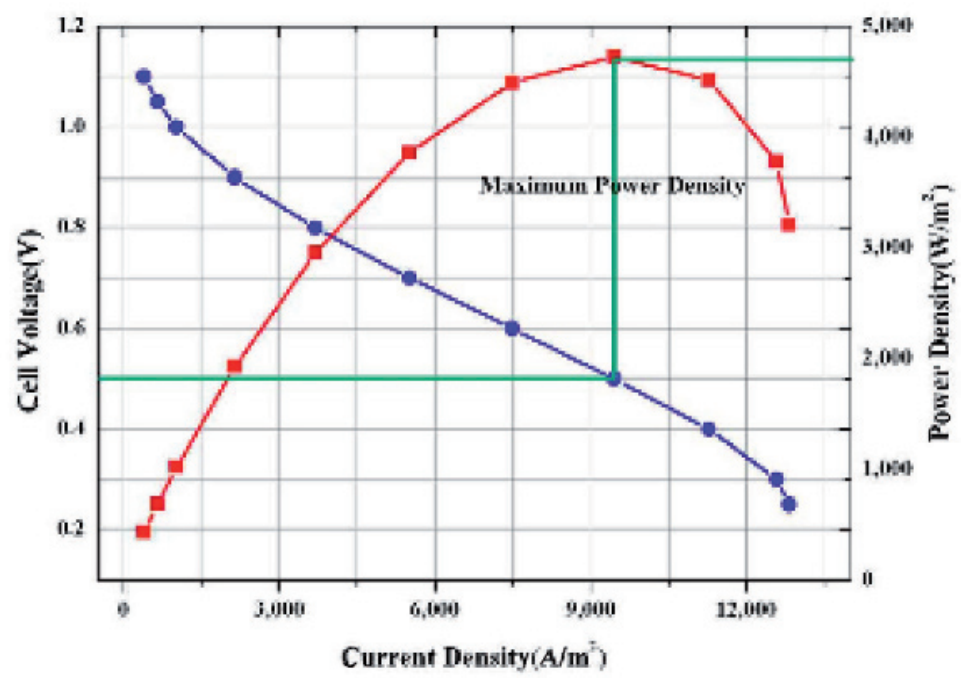

Fig. 6. - Fuel cell operating characteristics.

of each gas. Haber's coal gas was of course a mixture of hydrogen and carbon monoxide. Assuming hydrogen as fuel for simplicity, the cathodic and anodic reactions are given in table II and therefore the Nernst relationship becomes

$$
U_{0}=U^{*}-(R T / 2 F) \cdot \ln \left(P_{\mathrm{H}_{2}} \cdot P^{0.5} \mathrm{O}_{2} / P_{\mathrm{H}_{2} \mathrm{O}}\right) .
$$

The power of 0.5 for the partial pressure of oxygen reflects the fact that the oxygen ion is doubly-charged.

Where the hydrogen and oxygen partial pressures are each 1 atm., and at ambient temperature, the open-circuit voltage of the fuel cell, following table I, is $1.23 \mathrm{~V}$. Thermodynamically the enthalpy of hydrogen decreases with increasing temperature. Therefore for fuel cells with a high operating temperature the open-circuit voltage drops, to about $1.05 \mathrm{~V}$.

The current/voltage and power characteristics of a typical fuel cell operating on hydrogen are shown in fig. 6 . Since it is a low-temperature cell the open-circuit voltage is close to the theoratical value of $1.23 \mathrm{~V}$. There is a sharp gradient when a small current is drawn, following the exponential characteristic seen in fig. 4, and referred to as the

TABLE II. - Reactions of a fuel cell operating on hydrogen, the reverse reaction to electrolysis.

Cathode - oxygen reduction

Anode - hydrogen oxidation

Overall reaction

$$
\begin{aligned}
& \mathrm{O}_{2}+4 \mathrm{e}^{-} \rightarrow 2 \mathrm{O}^{2-}, \\
& \mathrm{H}_{2}+\mathrm{O}^{2-} \rightarrow \mathrm{H}_{2} \mathrm{O}+2 \mathrm{e}^{-}, \\
& \mathrm{H}_{2}+{ }^{1} /{ }_{2} \mathrm{O}_{2} \rightarrow \mathrm{H}_{2} \mathrm{O} .
\end{aligned}
$$


activation overpotential. Thereafter the characteristic becomes more linear, as the resistance of cell components becomes more dominant in the loss mechanisms. Finally at higher currents there is a further sharp decline, representing depletion of the available fuel or oxidiser, giving a concentration polarisation. Since output power requires both a significant current and voltage, there is a clear peak in the cell power output. However the enthalpy of the fuel remains constant, so as the voltage drops, the overpotential represents an efficiency drop and increasing thermal losses. In the example given above, the power peak occurs at an output voltage of $0.5 \mathrm{~V}$, and therefore at an efficiency of $40 \%$. For high overall efficiency fuel cells are usually operated at low overpotential, with an output voltage of 0.7 or higher, giving an efficiency of close to $60 \%$

\section{5. - Fuel cell implementation}

Several systems implementing the fuel cell concept have been developed, differing in materials, operating temperature and fuel requirements. Any primary battery is essentially a fuel cell: electricity is generated by an exothermic reaction, an example being the standard Léclanché cell where metalic zinc is the fuel. However in a battery the electrodes react electrochemically, whereas in a fuel cell there is the electrochemical reaction of liquid or gaseous reagents continuously supplied to dimensionally stable electrodes. For 50 years after Grove/Schonbein, their device was known as a "gas battery". The name changed to "fuel cell" (Brennstoffzell) when Ludwig Mond and Charles Langer worked on a coal-gas device (1889), their ideas possibly influencing Ostwald. Incidentally, there are still occasional publications on coal in fuel cells, e.g. "Regenerative coal-based solid oxide fuel cell/electrolyser", S. Gopalan, G. Ye and U. B. Pal, J. Power Sources, 162 (2006) 74-80. Table III presents the principal technical implementations of the fuel cell concept currently under development.

5`1. The alkaline fuel cell. - This was developed in England by Francis Bacon who demonstrated a $5 \mathrm{~kW}$, 40 cell series-connection "stack" with an efficiency of $60 \%$ using hydrogen fuel in 1959. His development was licensed for aerospace requirements and was applied in the Apollo spacecraft and in the Shuttle, fig. 7. Bacon chose an alkali metal hydroxide solution, typically $\mathrm{KOH}$, as electrolyte since he found with the materials and catalysts of the time that overpotential losses were lower than with acid systems. For spacecraft, fuel cells were an ideal solution to the power supply problems for long manned flights such as the moon missions where use of solar cells was impracticable and standard batteries lacked capacity. Hydrogen and oxygen were already available on board, and the water produced in the cell supplied crew requirements.

With reference to table III, it is evident that this type of cell relies on the mobility of the hydroxyl ion in the electrolyte. A continuous supply of water at the cathode is required to reduce molecular oxygen to hydroxyl. However the anode reaction produces excess water which can be recycled to the cathode. To separate the gases the electrolyte is contained in a porous separator matrix, originally asbestos. Reagent and ion transport in an alkali fuel cell are represented in fig. 8. Although the alkaline fuel cell was used in 
TABLE III. - Schematic representation of current fuel cell systems technologies.

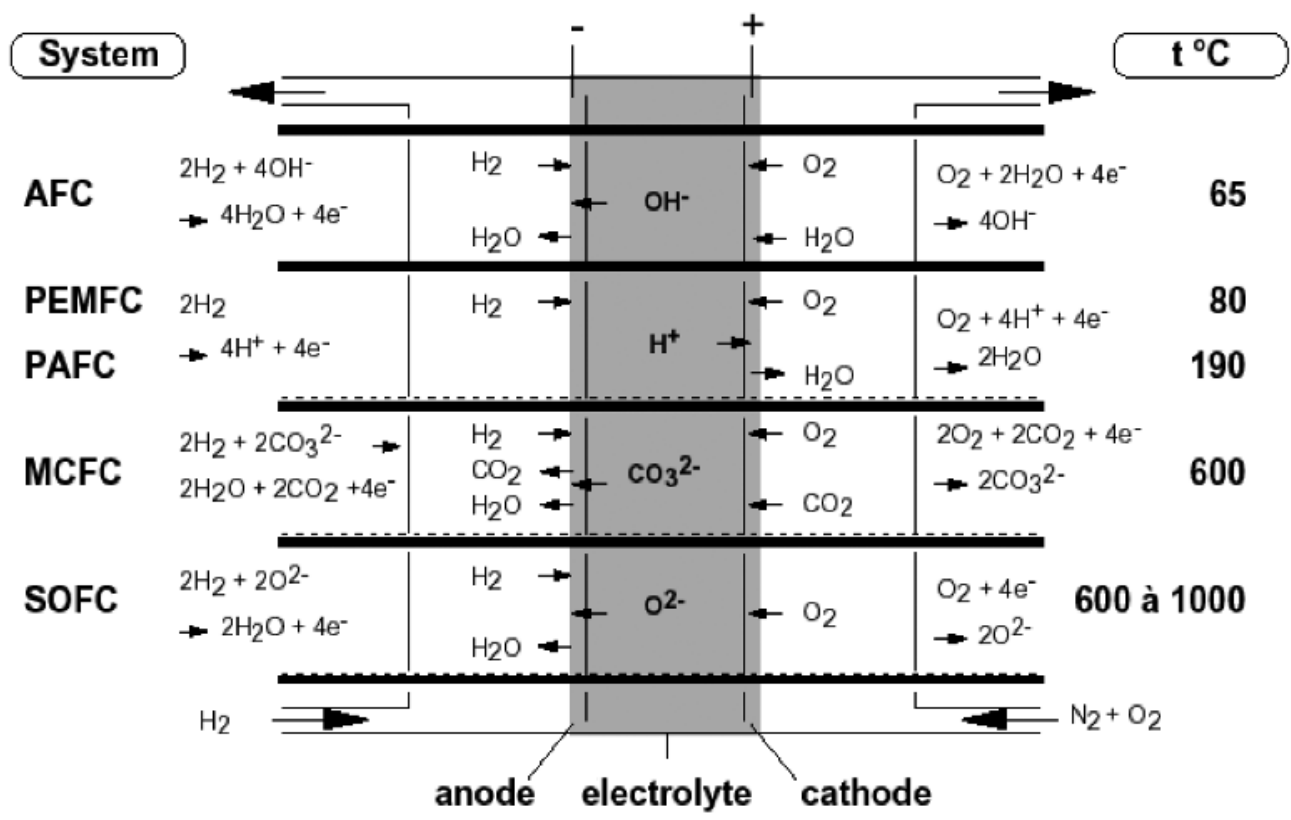

his own car by Karl Kordesch in 1970, it has found few terrestrial applications. Despite its efficiency, a limiting factor is the presence of carbon dioxide in air. Therefore if the cathode volume of a cell is supplied with air rather than pure oxygen, the alkaline

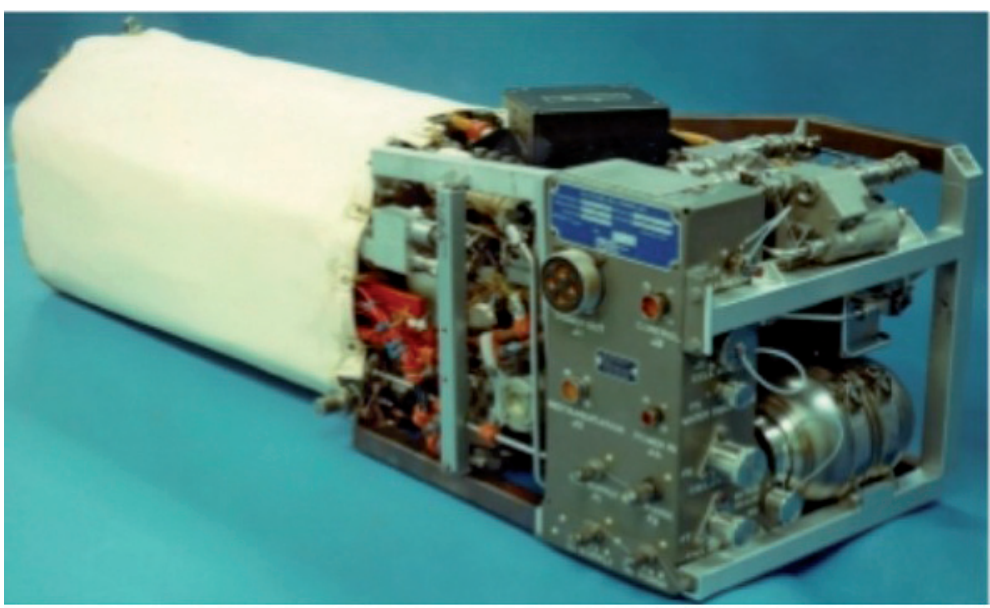

Fig. 7. - NASA $12 \mathrm{~kW}$ alkali fuel cell for Space Shuttle missions. 


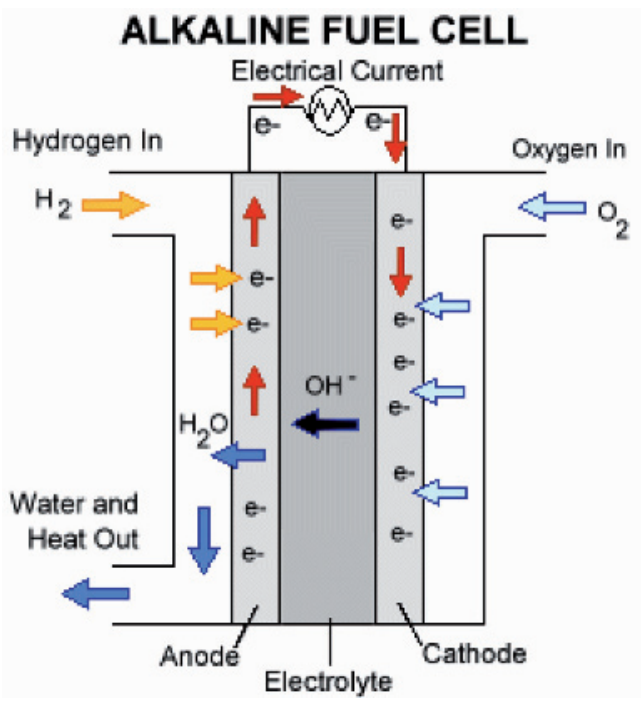

Fig. 8. - Gas and ion transport in an AFC.

electrolyte will gradually be neutralised. In particular, potassium carbonate, $\mathrm{K}_{2} \mathrm{CO}_{3}$ will deposit in the pores of the separator, deactivating the system.

$5 \cdot 2$. The polymer electrolyte fuel cell. - The fuel cell variant currently favoured for vehicles is the polymer electrolyte (or proton exchange membrane) fuel cell, PEFC or PEMFC. Developed in the 1960's, again for aerospace, PEFC devices actually preceeded the APC into orbit as the power source for the Gemini spacecraft. The membrane is nonpermeable to molecules, and therefore acts as a separator between fuel and oxidant gases. The early cells had a short lifetime since the membrane, based on hydrocarbon, was liable to attack in the highly oxidising environment of the anode. Also, while hydrogen is easily ionised on a platinum catalyst, oxygen is much less active. To limit overpotential losses the early cells used a high platinum loading. The breakthrough was the introduction of the nafion ${ }^{\mathrm{TM}}$ fluoropolymer, in which sulfonate groups are introduced into the polymer chains. Like the related teflon, nafion ${ }^{\mathrm{TM}}$ is highly inert chemically, but the acid sites provide a transport mechanism for ions. Much higher platinum dispersion on carbon fibre electrodes, attached by thermocompression bonding to the electrolyte to provide a rugged membrane-electrolyte assembly or MEA, make present-day PEFC systems much more reliable and economically attractive.

However, like the AFC, there are drawbacks. Figure 9 shows the mobile ion as $\mathrm{H}^{+}$. In fact, given the small size of that ion, its affinity for polar molecules is high and it is generally associated with one or more water molecules, making a hydronium ion, $\mathrm{H}_{3} \mathrm{O}^{+}$. As a result, the operating temperature of the cell is limited to $<100{ }^{\circ} \mathrm{C}$. Also the ion current also transports water from anode to cathode. If any part of the electrolyte is deprived of water, local heating quickly degrades it leading to cell failure. In addition the catalyst is highly sensitive to the presence of carbon monoxide, in concentrations of parts per 


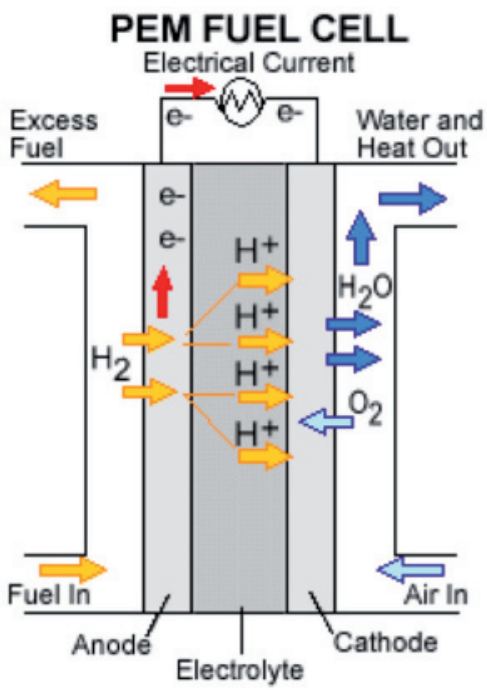

Fig. 9. - Gas and ion transport in a PEFC.

million. Since commercial hydrogen is normally produced from natural gas, some trace presence of $\mathrm{CO}$ is inevitable. While this can be minimised by selective oxidation to $\mathrm{CO}_{2}$ or reduction to $\mathrm{CH}_{4}$ the process is not simple or inexpensive. In practice the preferred fuel for PEFC is therefore electrolytic hydrogen, and a closed system results: electrolysis to produce the fuel, then the PEFC to consume it for electricity production. This is only justifiable for particular applications, for example a fixed electrolyser producing storable hydrogen for a vehicle, or "renewable" electricity being stored as hydrogen for night or low-wind recovery.

A variant of the PEFC is the direct methanol cell, DMFC. Here a liquid fuel, in principle "renewable", is directly oxidised to water and carbon dioxide on a MEA. Its limitations are the low current density available, and the fact that Nafion ${ }^{\mathrm{TM}}$ is not totally impermeable to methanol, creating a "chemical short circuit" of the cell which significantly lowers the output voltage and efficiency. This cell may find some role in powering portable electronics, for example, but it cannot provide the power density for a practical road vehicle.

5.3. The phosphoric acid fuel cell. - This concept was favoured for some time, since it does not have the temperature limitation of the PEFC system. With the high affinity of the acid for water, the cell can remain humidified up to $200{ }^{\circ} \mathrm{C}$. The catalyst is therefore thermally activated, and the tolerance to carbon monoxide is significantly increased. Pretreatment of hydrocarbon fuel such as natural gas is greatly simplified, and commercial hydrogen is an acceptable fuel. The PAFC being an acid cell, the gas and ion transport processes are analogous to those of the PEFC, fig. 9. However the elevated temperature acid environment is corrosive, the degradation being enhanced by gas cavitation at the 


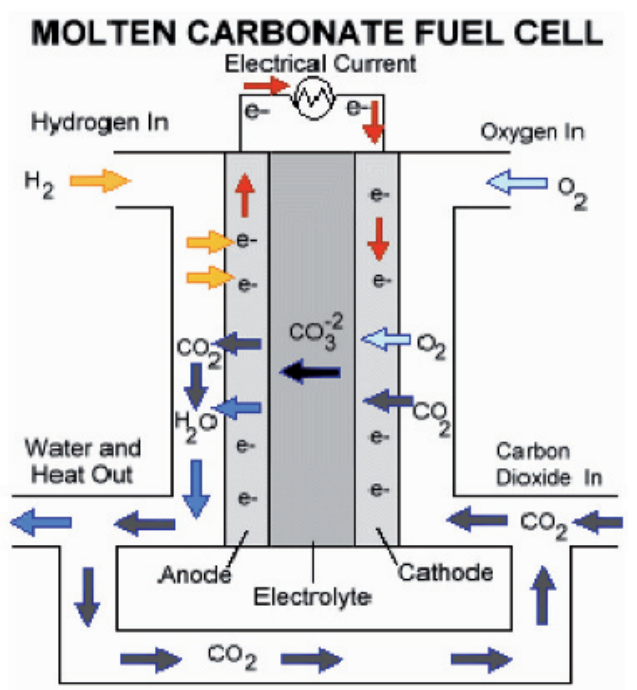

Fig. 10. - Gas and ion transport in a MCFC. Note the recycling of carbon dioxide from anode to cathode as required for the formation of the ionic oxygen vector, the carbonate ion.

electrode structures. Given these limitations, PAFC development and implementation are practically at a standstill.

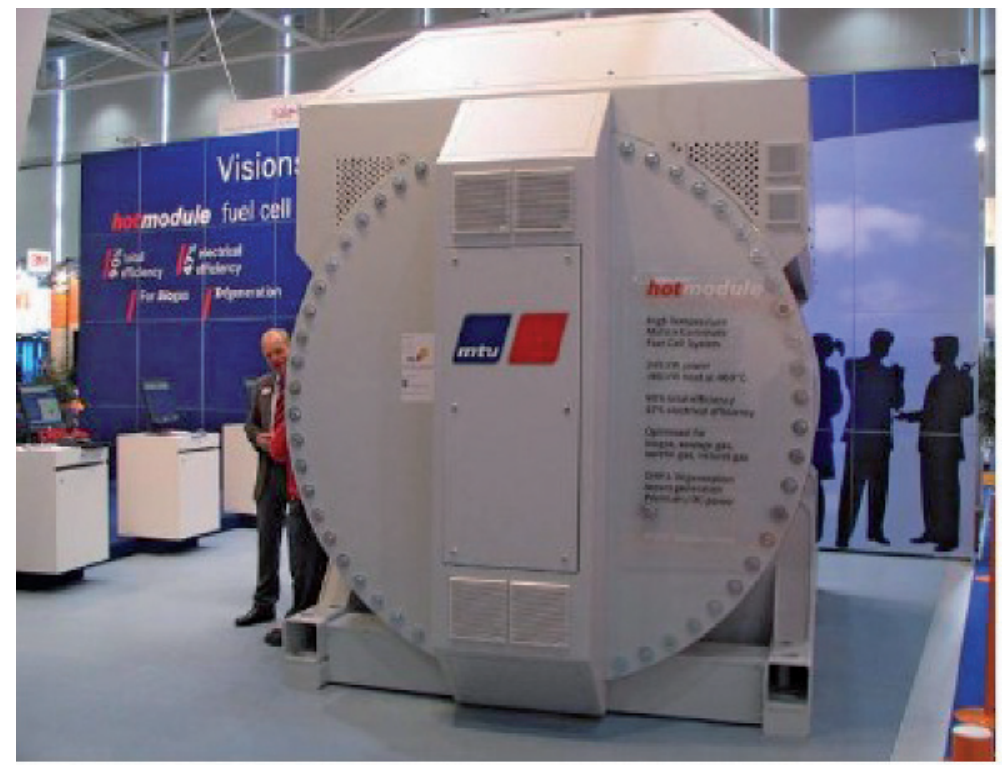

Fig. 11. - MCFC unit rated at $240 \mathrm{~kW}$ electrical output, as presented at the Hanover Fair, 2006. 
5*4. The molten carbonate fuel cell. - This is a system for further exploiting thermal activation of the electrochemical processes of a fuel cell, given an operating temperature of $600{ }^{\circ} \mathrm{C}$. At this temperature, well about the melting point of a salt mixture, there is a high mobility of the ions and therefore the possibility to use it as an electrolyte. The salts in question are the carbonates of lithium and potassium. The carbonate ion acts as a vector for oxygen, so that it can be transported from the cathode to the anode, where it can react either with hydrogen or with carbon monoxide. This liquid salt mixture is entrained in the pores of a ceramic tile, usually zirconia. Held by capillary forces, it forms an adequate barrier between fuel gas and oxidant air. Commercial hydrocarbon fuels, by preference natural gas, can be reacted simply with steam in the "reforming reaction" to produce a hydrogen-carbon monoxide mixture ideal for oxidation at the MCFC anode to produce steam and carbon dioxide:

$$
\mathrm{CH}_{4}+\mathrm{H}_{2} \mathrm{O} \rightarrow \mathrm{CO}+3 \mathrm{H}_{2}
$$

The availability of excess carbon dioxide is a further advantage of this fuel mixture. The formation of the negatively charged carbonate ion, $\mathrm{CO}_{3}{ }^{2-}$, at the cathode requires reaction with carbon dioxide which must be made available, preferably by gas recycling from the anode as shown in fig. 10. Controlling and maintaining the appropriate flow of carbon dioxide is a systems management complication for the MCFC. Several large-scale units have been installed and evaluated, as shown in fig. 11.

5.5. The solid oxide fuel cell. - Another high-temperature fuel cell concept, the solid oxide device, has all the advantages of the MCFC, while avoiding the systems complications of controlled carbon dioxide recycling. In this case the mobile ion is that of oxygen as it moves between crystal defect sites in an oxide ceramic, normally based on zirconia, $\mathrm{ZrO}_{2}$ or ceria, $\mathrm{CeO}_{2}$. A small proportion of the 4-valent ion in the crystal is replaced by a trivalent species, yttrium in $\mathrm{ZrO}_{2}$ or gadolinium in $\mathrm{CeO}_{2}$. Charge neutrality requires that the trivalent sites be compensated by vacant oxygen sites or defects. Oxygen ions transferred between vacancies constitute an oxygen transport mechanism (fig. 12). Since oxygen mobility is thermally activated, the resistance of the electrolyte drops rapidly as the temperature increases, as does the activity of the electrodes.

High-temperature operation requires selection of specialised materials, both for electrodes and for structural components. Only noble metals can withstand the cathode environment without oxidation, so the standard cathode is an electrically conducting ceramic oxide, usually a lanthanum-strontium manganite, LSM, $\left(\mathrm{La}_{x} \mathrm{Sr}_{1-x}\right) \mathrm{MnO}_{3}$. As with the electrolyte, the lower-valence strontium component induces oxygen vacancies in the crystal lattice. LSM is therefore an effective electrocatalytic cathode surface, as it is both an electronic and an oxygen ion conductor. On the anode side, given the presence of fuel, a porous nickel structure is satisfactory. The porosity permits the diffusion of fuel to the electrode-electrolyte interface and the evacuation of oxidation products, steam and carbon dioxide. However the fuel must be pretreated with steam as for the MCFC, providing a hydrogen-carbon monoxide mixture, because hydrocarbons deposit 


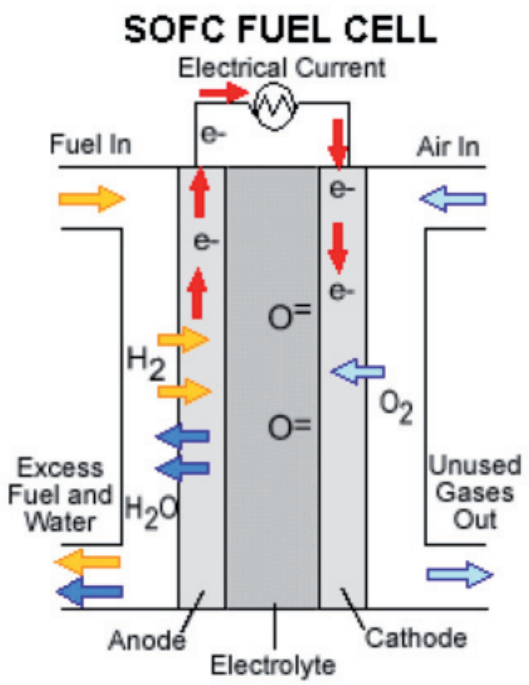

Fig. 12. - Gas and ion transport in a SOFC.

carbon on the metal, blocking the porosity and even disrupting the structure. Also at elevated temperatures and under reducing conditions, porous nickel tends to sinter, a further mechanism to close off porosity. The practical anode now used is a cermet, a

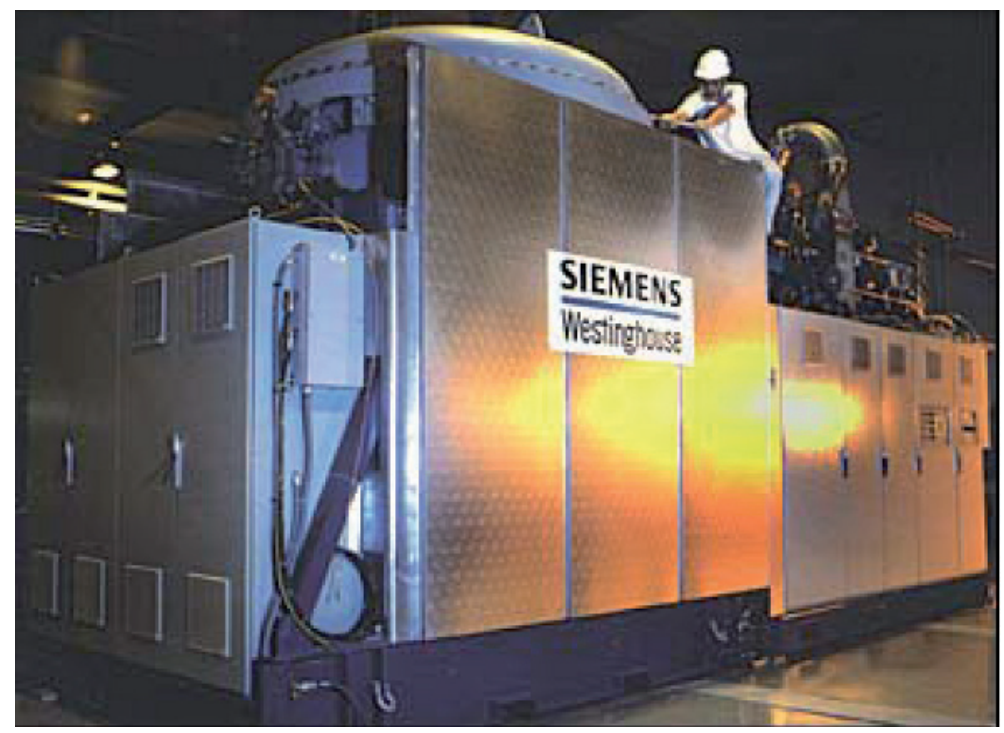

Fig. 13. - Prototype $220 \mathrm{kWe}$ combined cycle SOFC/steam turbine generator set. The presssurised enclosure for the fuel cell is in the foreground. 
composite structure of fine-grain nickel and zirconia, which has a demonstrated stability with porosity maintained for the operational lifetime of the SOFC system. Obviously also, very high-temperature systems must be carefully insulated, and heat management is a challenge, involving heat recovery from the exhaust gas for the fuel processing step. There has also been a demonstration of a combined cycle plant, where recovered heat raises steam for a turbogenerator set (fig. 13). A significant application opportunity is for a home-scale combined heat and power (CHP)device, providing a few $\mathrm{kW}$ of electricity while also supplying the heating and hot water requirements of the occupants.

\section{6. - Present status of fuel cells}

The principal concepts for the realisation of fuel cell generating systems have been presented, and it is clear that while each has its specific advantages there are also factors which severely limit applications. The low-temperature cells are obviously more adapted to portable and mobile use, but present very severe electrocatalysis requirements, requiring materials with, unfortunately, high sensitivity to fuel impurities. They are flexible, with rapid start-up times, fast response to changing electrical demands, compact with a reasonable power density and therefore compatible with vehicle drive trains, quiet and increasingly reliable. Fuel cell powered cars, buses and other vehicles have been demonstrated. The limitation is the availability of an infrastructure able to supply fuel cell quality hydrogen with the same convenience as regular motor fuel. In consequence there is no large-scale manufacture of low temperature fuel cells.

There is a similar situation for the high-temperature devices. The concepts are proven, but the materials required are specialised, and the systems comprising the balance of plant such as fuel processing, sensors, control, and thermal balance are complex. The applications foreseen are for fixed installations. On the domestic scale a CHP must be fully automated and fail-safe, with low maintenance demands and sufficiently low cost to compete effectively with conventional systems for home electrical and thermal requirements. Prototype units have been demonstrated, but their high efficiency does not yet justify the investment and long-term reliability remains to be established. On an industrial scale large SOFC generator sets face similar problems. With the ancillary systems they are much larger than equivalent electromechanical units. Some progress is evident, with $200 \mathrm{kWe}$ units being on commercial offer from Bloom Energy, USA. Cost and operational experience including personnel training are still inhibiting factors.

It could be suggested that niche markets should be developed, so that the fuel cell operation can be established as practical and economically advantageous, with a gain of fabrication and operating experience. A prime example is the recent commissioning of a 1 MWe fuel cell unit at the Antwerp plant of the Belgian chemical company Solvay. Large-scale brine electrolysis is carried out to provide chlorine for PVC manufacture; fuel cell quality hydrogen is a by-product with which the fuel cell can generate electricity. 


\section{7. - Conclusion}

This review has focussed on fuel cells as an example of an electrochemical-energy production process, presenting it in its historical context and taking into account the recent emphasis on research and development of energy conversion systems. Primary and secondary batteries are another energy-related area, and the recent breakthroughs in lithium cells with their unprecedented energy and current densities are not to be overlooked. Transient energy storage can be associated with electrolytic supercapaciitors. Solar-energy conversion with dye-sensitised photoelectrochemical cells is in competition with conventional solid state photovoltaics, providing a stimulus to improvement of both concepts. Then there is the issue of energy conservation in industrial electrochemical systems, including electrochemical metallurgy. The carbon anode of a Hall-Herault cell for aluminium production can be regarded as a fuel cell, since with its oxidation to carbon dioxide the potential required by the cell is reduced by $1 \mathrm{~V}$, minimising fluorine emissions from the elecrolyte. Obviously then there are increasing opportunities for electrochemistry to contribute to our energy economy and to environmentally favourable industrial processes. Despite that, it must be admitted that we are still far from realising Ostwald's vision of a combustion-free world.

\section{Further reading}

- Shukla A. K. and Kumar P. T., Pillars of Modern Electrochemistry, Electrochem. Soc. Interface, 17 (2008) 31.

http://electrochem.cwru.edu/encycl/art-p05-pillars-of-ec.htm

- Hamann C. H., Hamnett A. and Vielstich W., Electrochemistry (Wiley-VCH, Weinheim, DE) 2007, ISBN 978-3-527-31069-2.

- Lefrou C., Fabry P. and Poignet J.-C., Electrochemistry (Springer, Heidelberg) 2012, ISBN 978-3-642-30250-3.

- O’Hayre R., Cha S.-W., Colella W. and Prinz F. B., Fuel Cell Fundamentals, 2nd edition (Wiley, New York) 2009, ISBN 978-0-470-25843-9. 